\title{
Essence and Strategies of Grasping the Emotional Tone of the Dance
}

\author{
Shu Jia \\ Zaozhuang University \\ Zaozhuang, China 277000
}

\begin{abstract}
In the dance works, emotion is an important issue which cannot be ignored by every performer. Only by accurately grasping the emotional tone of the dance can the emotion be transmitted to the audience through accurate body movements. In order to explore the way to grasp the emotional tone of the dance, the author first analyzed the nature of the emotional tone of the dance and discussed the specific strategy to grasping it from four aspects, including the knowledge background of the dance work, the capture of the image, the digging of the color music and the contradiction processing of the emotional tone.
\end{abstract}

Keywords—dance; emotion; essence; grasp

\section{INTRODUCTION}

Dance is a very vivid art. Emotion is an indispensable part of the dance. In the dance performance, we must fully grasp the inner tone of the dance in order to fully display the connotation of the dance and infect the audience [1]. However, there are great differences in the emotional tone of different dances. In the secondary creation of dance, performers shall grasp the intrinsic essence of the emotional tone in order to effectively grasp the inner emotional tone.

\section{THE ESSENCE OF THE EMOtional TONE OF THE DANCE}

The essence of dance is emotion, and the emotion of dance is embodied in the emotional experience obtained by the performer on the study of the role in the dance before the performance, as well as the understanding of the emotion of the dance displayed in the performance. For the performers, the dance emotion is actually the emotion of the role that the performer understands in the dance. It can be completely separated from the dance itself in form, but it cannot be based on the emotion of the actor alone. Therefore, the emotion in dance performance is based on the role of dance, and the role is not the ancillary of dance performance [2]. From the actual effect of dance performance, performers, dance work and role emotion have some common features. The performers can only deeply feel the emotional tone of the characters in the dance works to integrate emotion into their dance movements and show them in front of the audience.

In dance, emotional experience and emotional expression are interdependent and cannot completely exist independently. If the performers are unable to form their own emotional tone when performing dance performances, they will never be able to affect this emotional tone to the audience. As the leader of the dance performance, the performers shall analyze the commonness of the role's inner character conflicts and sublimate the commonness to the height of the emotion, and embody it in a similar way [3]. The performers can only achieve the emotional tone of the dance through a lot of experience, and turn it into a basic view of the dance performance, and finally display the emotional tone by body movements. The performer's emotional experience is sometimes caused by self emotional impulse, but sometimes it is inspired by the specific elements of the dance works. Performers need to consciously combine the emotional tone of dance with the expression of dance movements, and gradually realize the organic integration of emotional expression and dance movements, making the dance performance more vivid and reflecting the inner art life of the dance.

As the precursor of performers' performance, the emotional tone can optimize the performers' performing movements, and also determine the way in which the dance performance should be carried out in the specific circumstances, which fundamentally embodies the specific direction of the dance. Although sometimes the emotional tone cannot be reflected through intuitive dance movements, it is unquestionable that the emotional tone of the dance can effectively break the original emotional balance in the performers' hearts, thus guiding the expression of the dance movements.

To sum up, the emotional tone is a prerequisite for the dance performance. Only by accurately grasping the emotional tone of the dance works, the performers can embody the inner feelings of the dance works through the movement of the body.

\section{THE STRATEGIES OF GRASPING THE EMOTIONAL TONE OF THE DANCE}

The emotional tone of different dance works has its own characteristics. Some are absurd; some are funny; each one is different. Emotional tone is an abstract factor that needs to be attached to specific characters. The accurate grasp of the emotional tone of the dance is the key to the performers' dance performance. The performers shall explore the specific ways to express the emotional diversity through specific limb movements before performance. 


\section{A. Starting with the Knowledge Background of the Dance Works}

The dance works are a product of socialization. The emotion expressed by the dance is bound to be influenced by the social environment of the time. When the emotional tone of the dance works is grasped, it must be placed under the specific social environment of the works to understand the emotions and forms that they should grasp. If the performers want to create a good dance figure, they shall understand the historical environment of the character image, experience the social stratum and national character of the figure, because anyone has the basic characteristics of social and national nature, and their feelings inevitably have these characteristics [4]. For example, the dance of the Han Dynasty tended to pay attention to strength and vitality. Therefore, the dance of the Han Dynasty was mainly a hyperbole of dance movements, which reflected the magnificence of momentum and the beauty of movement. Therefore, when performing dance performances of the Han Dynasty, performers should pay attention to the shaping of imposing beauty and showing a kind of simplicity and tension. Only by starting from the knowledge background of dance works can performers express its inner deep emotional tone. For example, in the dance Begonia, the living age of the figure Begonia is the period of the Republic of China. Under the social environment of that time, the Peking Opera artist belonged to the bottom of the society and as an extremely humble profession. Starting with the social background of the characters, it can be found that the emotional tone of the whole dance works cannot be simply taken from the tone of "sorrow", and at the same time, it is necessary to embody the persistence of the artists at the bottom of the society.

To start with the knowledge background of dance works, it is necessary to start with the following two aspects: first, analyze the emotional tone of the dance from the paragraphs and levels of the dance works, which requires the performers to go deep into the interior of the dance works. Take the analysis of Begonia as an example. In the work, a large number of allegro and adagio are set to express character characteristics and emotional tone. The allegro mainly is to embody the protagonist's prosecution of the fate. In fact, it is a complaint against the local warlords. The adagio is to show a sentimentally attachment of Begonia to the stage. Different emotional tones of the role are highlighted by the contrast of allegro and adagio. Second, grasp the emotional tone of the work from the name of work. The name is a summary of dance works, which can effectively give feedback of the emotional tone of the dance works. Many dances have set the names that can effectively express their emotional tone, so as to make the finishing point. Take Injustice to Dou E as an example. From the name of the work, it can be seen that the dance work is express a feeling of resentment. In addition, from the name of Farewell, it can be seen that the dance works express a kind of parting and lovesickness. Performers need to use soft movements to express the inner and delicate feelings of the characters.

\section{B. Strengthening the Capture of Image}

The emotional tone of the dance works can only be reflected by a certain figure, so only by strengthening the capture of the image can performers effectively grasp the emotional tone of the works [5]. In the end, to strengthen the capture of image of the characters is to grasp the emotions of the different roles clearly. Only the accurate grasp of the character image can make the emotion with a clear direction. For example, the image of the old people is often humpbacked and faltering, while the image of the hero is magnificent and brave. If performers cannot express the emotions of different roles clearly, it will be inevitable for performers to deviate from the emotional tone of the dance. For example, in The Flash Red Star, the hero Pan Dongzi's image is set as a child. The performer shall grasp the characters of child and express the emotion on this basis. If the performer cannot grasp the emotional tone from the angle of the children, it will inevitably lead to the distortion of the movement and cannot effectively express the emotional tone of character. Therefore, to strengthen the capture of image is an important way to grasp the emotional tone from the characters' hearts.

Second, the image movement is also an important factor in reflecting the emotional tone. The image movement maybe only is an action, or they maybe are a series of movements, which can not only directly reflect the basic characteristics of the characters, but also have a strong emotional color. Therefore, performers can grasp the emotional tone of the whole work only by grasping movements with the strong emotion in the work. The image action is often summed up by the way of refining in the choreography. It is the basic action that can reflect the character's characteristics and emotional characteristics most deeply. Under the same circumstances, it will appear many times in dance works, and there will be a lot of music to render it. For example, the action of standing on tiptoe in Rouge Buckle and the action of playing the piano in Ode to Long River can effectively give feedback of the emotional tone of the work. The accurate grasp of the image action is not only the task that must be accomplished in the dance performance, but also can promote the performers' inner feelings to resonate and induce their emotional expression. For example, in Moon Night of Spring River, there is a classic action of a maid. The maid half covered her face with a fan and looked around. This series of movements can effectively express the beauty of the maid and at same time performers can grasp the emotional change of the maid.

\section{Digging the Color of Music}

Music is an essential part of the dance. It is an important way to reflect the rhythm and emotion of the dance. It can also bring an auditory stimulus to the performers and stimulate the performers to express corresponding emotions. Secondly, the most important meaning of music in the dance works lies in the creation of artistic conception. The performer should start and associate with the artistic conception created by the music, experience its emotional tone and achieve the overall transition from music to dance and from dance to music [6]. From the analysis of Moon Night of Spring River, it can be found that the music rhythm is very clear. It follows the basic rhythm from slow to fast. The beginning of the dance mainly are dance 
movements of small amplitude, and the later stage is gradually turned to the climax, and a large number of lyric dance segments gradually appear, followed by the quick rhythm of the music. From the change of music, it can be found that the emotional tone of the work shifted from plain to lyric gradually.

Secondly, in order to more accurately grasp the emotional tone of the works, performers shall complete emotional changes under a certain limit. The author has consulted a large number of relevant literatures, and carried on deep thinking, and thought that it is necessary to start from the following aspects: first, music can be used as a background environment for emotional expression. At this time the emotion is directly embedded in the music. Second, the emotion will change with the change of the music. And the two show a clear positive correlation. Third, in a specific part, emotional changes may follow its own internal logic, thus weakening the preceding relation of emotion and music. But the contrast is to highlight the emotion. For example, in many dances, the music will be delayed. When the dance is still in progress, the music does not stop, and the music rhythm is accelerated [7]. Last, analyze according to the emotional logic. It comes mainly from the emotional experience of the performer and the emotional experience of the audience.

\section{Processing the Internal Contradictions of the Emotional Tone}

Not all of the dance works have the unique emotional tone. The emotional tone of many dance works is relatively complex and even completely contradictory, which requires the performers to deal with the contradictions in the emotional tone of the works. To handle the emotional tone is mainly starting from the following aspects: first, strengthen the overall perception of the work and accurately grasp the emotional tone. For example, in Waves, the overall emotional tone is not afraid of hardships. The performers should embody the surging of the waves while performing, but more should reflect the fearless spirit of the petrel, and show the contradiction between the waves and the petrel through a strong movement. In other words, the surging of the waves can be expressed deeply, meanwhile the stubborn spirit of petrel can also be highlighted. Performers can transplant their emotions to the petrel and grasp the emotional tone of the work from the perspective of petrel. Second, seize the key points and solve the contradictions. In dance performance, the performers shall grasp the key points and solve the contradictions. They need to focus on the dance movements that can highlight the feelings of the characters. For example, in Begonia, the old man presents four distinct emotions in the memory of his life, but the most prominent emotion is expressed in the struggle for fate and strike of cruel reality. The performers shall accurately grasp the emotion in this part [8]. Third, strengthen the structure hackling of the works and analyze the emotion of work through logical analysis. In any dance movement, emotions are not invariable, and there are obvious ups and downs. But this undulation is not completely unchangeable, and all of them follow the law of emotional change and the law of choreography. The performer shall systematically comb the structure of the work before the performance, analyze the emotion of work according to the existing knowledge and emotional logic, and accurately grasp their emotional tone. For example, in Begonia, the emotional changes are clearly divided into four stages: "starting", "bearing", "turning" and "closing". Through logical analysis, it can be found that "turning" is the key part of the expression of emotional tone.

\section{CONCLUSION}

In any artistic creation and artistic behavior, emotion has a very important position, and the understanding of emotion directly restricts the specific direction and method of art expression. Dance is a kind of art that expresses human emotion by body movement. Its inner emotion is relatively rich, and it can only express the inner emotion through body action. Therefore, the dance performers shall accurately grasp the emotional tone of the works through specific methods, so that the emotion of the characters in the works can be effectively expressed through specific body movements.

\section{REFERENCES}

[1] Liu Naitian. Add More Emotion to Dance between Mellow and Full Music Play - Analyzing the Relationship between Music and Dance from the Combination of Dance music and Plot. Economist, 2012, (02): 146-147.

[2] Fan Xinghua. Hidden Emotions - Importance of Structure and Detail to Emotional Expression in Dance. Journal of Beijing Dance Academy, 2010, (01): 48-51.

[3] Luo Ying. From Autumn, Fan Framework and Moonrise by the Sea Practice and Reflection on the Depth Training of the Ability of Dancing Performance. Journal of Beijing Dance Academy, 2009, (01): 59-65.

[4] Yin Jianhong, Jiang Dong. Original Ecological Complex and Changes of Time of Chinese Folk Dance - From the Perspective of Yang Liping's Art Creation. Journal of Beijing Dance Academy, 2009, (01): 85-91.

[5] Dong Zhenqiong. Artistic Characteristics of Dance Movements - How to Improve Students' Ability to Grasp Action. Journal of the Art Academy of PLA, 2007, (04): 86-88.

[6] Shi Yanjing. The Most Real Dance - Appreciating Yi-dance Nuo Su Re an Award-winning Work of the 4th CCTV Dance Competition, Journal of Beijing Dance Academy, 2007, (02): 103-106.

[7] Lin Lin, Li Wei. The Creation of Dance Image - the Relationship between the Choreographer, the Dancers and the Audiences. Journal of Beijing Dance Academy, 2007, (02): 107-109.

[8] Ping Xin. Dance and Empathy - Expression, Presenta tion and Embodiment of Dance Art. Journal of Beijing Dance Academy, 2006, (04): 53-59. 